\title{
The Ideal Criteria of Supplier Selection for SMEs Food Processing Industry
}

\author{
Rohaizan Ramlan ${ }^{1}$, Engku Muhammad Nazri Engku Abu Bakar ${ }^{2}$, Fatimah Mahmud ${ }^{3}$ and Hooi Keng Ng${ }^{1}$ \\ ${ }^{1}$ Department of Production and Operations, Universiti Tun Hussein Onn Malaysia, Malaysia \\ ${ }^{2}$ Department of Decision Sciences, Universiti Utara Malaysia, Malaysia \\ ${ }^{3}$ Faculty of Industrial Management, Universiti Malaysia Pahang, Malaysia
}

\begin{abstract}
Selection of good supplier is important to determine the performance and profitability of SMEs food processing industry. The lack of managerial capability on supplier selection in SMEs food processing industry affects the competitiveness of SMEs food processing industry. This research aims to determine the ideal criteria of supplier for food processing industry using Analytical Hierarchy Process (AHP). The research was carried out in a quantitative method by distributing questionnaires to 50 SMEs food processing industries. The collected data analysed using Expert Choice software to rank the supplier selection criteria. The result shows that criteria for supplier selection are ranked by cost, quality, service, delivery and management and organisation while purchase cost, audit result, defect analysis, transportation cost and fast responsiveness are the first five sub-criteria. The result of this research intends to improve managerial capabilities of SMEs food processing industry in supplier selection.
\end{abstract}

\section{Introduction}

Food processing industry is identified as a top priority for industrial development and it will be expanded and diversified towards making Malaysia a regional food production and distribution hub during the (IMP3) period between 2006 until 2020 [1]. The food processing industry is dominated by small and medium scale companies where sectors are the fish processing and canning, processed meats, confectionary, canned fruits and vegetables, dairy products, noodles, bread and other bakery products [2].

The increasing trend of Malaysian standard of living, lifestyle and purchasing power have resulted to increase the demand for convenience food which in turn has led to more establishments of food-processed based SMEs in the Malaysia [3]; [4]. Therefore, availability of raw materials is essential to produce food processing products [5]. Unfortunately, this is the main problem faced by SMEs food processing industry in Malaysia which is raw materials are of substandard grades because of inconsistency in supply and availability of suppliers [6].

Supplier plays an important role in the food processing industry that provides the machineries, equipment, after-sales maintenance services and especially the raw materials [4]. Ting and Cho [7] stated that the selecting ideal supplier made by purchasing department of food processing industry has a direct effect on cost reduction, flexibility and profitability of company.

The objective of supplier selection is to identify suppliers with the highest potential for meeting a firm's needs consistently [8]. Over the last decade the research community has extensively studied the problem of evaluating and selecting suppliers by adopting numerous multi-criteria decision support tools such as Analytic Hierarchy Process (AHP) model [9]; [10]. According to Ahmad and Pirzada [11], the application of AHP model is widely adopted decision supported technique. Therefore, this research aims using Analytical Hierarchy Process (AHP) model to determine ideal criteria of supplier selection in SMEs food processing industry.

Selecting the ideal supplier is a difficult mission for purchasing department of SMEs food processing industry due to suppliers have varied strengths and weaknesses that require careful assessment before making decision [12]. Ren and Song [13] stated that the SMEs food processing industry are always facing supplier selection problem.

However, SMEs food processing industries in Malaysia are paying too much attention on price offered by supplier lead to incorrect supplier selection [12]. Moreover, SMEs food processing industry in Malaysia are facing plenty of obstacles to stay as competitive industries in market such as lack of managerial capability [14] and a slower adopter of management practices at various levels for quality and operational improvement [15] that lead to incorrect supplier selection. Therefore this research aims to identify ideal supplier criteria for SMEs food processing industry using AHP model. 


\section{Literature review}

\subsection{Malaysia SMEs food processing industry}

Food processing industry is one of the important subindustries in the development of the manufacturing sector in the Malaysia and it has been identified as one of twelve prioritized industries in the Second Industrial Master Plan 2 (IMP2) and Third Industrial Master Plan 3 (IMP3) [1]. In the Industrial Malaysian Plan 2006-2020 (IMP3) period, the food processing industry's investment target have been set at RM24.6 billion (Ministry of International Trade and Industry, 2012, as cited in Ayupp and Tudin [16]). The following sub-sectors in Malaysia are the most important in the overall food processing industry, which are fish processing and canning; processed meats; confectionary; canned fruits and vegetables; dairy products; noodles, bread and other bakery products and processed meat [5].

Malaysian food industry is dominated by small and medium scale firms [17] that represent more than 80 per cent of the total number of establishments in the processed food segment [18]. According to Alam et al. [3], the numbers of SMEs food processing industry in Malaysia increased due to processed food products have become the choice of many Malaysians.

\subsection{Supplier selection in SMEs food processing industry}

Supplier plays a vital role in the food processing industry that provides the machineries, equipment, after-sales maintenance services and especially the raw materials [4]. Supplier selection process requires a correct guideline or adequate dimension of supplier's criteria to determine a suitable supplier [19].

The previous studies done by researchers conclude that five criteria with sub-criteria are used to evaluate food supplier. These criteria and sub-criteria are service (fast responsiveness, supply capacity and follow up), management and organisation (good reputation among industry, geographical location and financial status), cost criteria (purchase cost, transportation cost and operational cost), delivery (delivery reliability, delivery lead time and fill rate) and quality (audit result, defects analysis and documentation) ([20-23]; [10]; [24]). Thus, these five criteria and sub-criteria (Figure 1) are selected in this research to determine the ideal supplier of SMEs food processing industry.

\subsection{AHP in supplier selection}

The AHP was introduced by Saaty [25]. The AHP is one of the most well-known multi-criteria decision making (MCDM) methods to assist in the complex task of reaching the best decision from a set of possible criteria [26].

According to Kahraman et al., [8], selection is a broad comparison of suppliers using a common set of criteria and measures. These criteria include such as service (fast responsiveness, follow up and supply capacity), management and organization (good reputation among industry, geographical location and financial status), cost criteria (purchase price, transportation cost and operational cost), delivery (delivery reliability, fill rate and delivery lead time) and quality (audit result, documentation and defect analysis) ([20]; [21]; [22]; [23]). There are numerous studies done which summarizes the application of Analytic Hierarchy Process (AHP) model in decision making problems of supplier selection by Xia \& Wu [20]; Vijayvagy [21]; Shen, Liu, \& Tzeng [22]; Anyaeche \& Abegunde [23]; Reza, Essmaeel, Hossein, \& Mohammad [24]; Ramlan \& Lee [10].

\section{Methodology}

This study adopts a quantitative research approach, with questionnaires distributed to 50 respondents of SMEs food processing companies in Batu Pahat, Johor, Malaysia that has authority to make decision on supplier selection. The data is analysed using Expert Choice Software. In this study, the AHP implementation step was simplified by using the Expert Choice software. The following are steps for AHP method.

Step 1: Develop the matrix of criteria.

The problem is decomposed into a hierarchy of goal, criteria, sub-criteria and alternatives as shown in figure 1 .

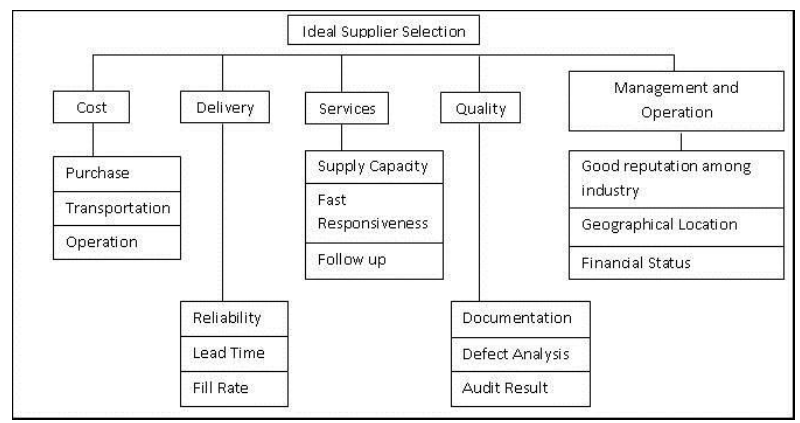

Figure 1. AHP model for this study.

Step 2: Make a pairwise comparison of alternatives on a qualitative scale.

Table 1. AHP pairwise scale [27].

\begin{tabular}{|c|c|c|}
\hline Intensity & Definition & Explanation \\
\hline 1 & $\begin{array}{l}\text { Equal } \\
\text { importance of } \\
\text { criteria }\end{array}$ & $\begin{array}{l}\text { Two criteria contribute equally } \\
\text { to the property }\end{array}$ \\
\hline 2 & Weak & \multirow[b]{2}{*}{$\begin{array}{l}\text { Experience and judgement } \\
\text { slightly favor one criterion over } \\
\text { another }\end{array}$} \\
\hline 3 & $\begin{array}{l}\text { Moderate } \\
\text { importance of } \\
\text { one criterion } \\
\text { over another }\end{array}$ & \\
\hline 4 & Moderate plus & \multirow[b]{2}{*}{$\begin{array}{l}\text { Experience and judgement } \\
\text { strongly favor one criterion } \\
\text { over another }\end{array}$} \\
\hline 5 & $\begin{array}{l}\text { Essential or } \\
\text { strong } \\
\text { importance of } \\
\text { one criterion } \\
\text { over another }\end{array}$ & \\
\hline 6 & Strong plus & \multirow[b]{2}{*}{$\begin{array}{l}\text { A criterion is very strongly } \\
\text { favored, and its dominance is } \\
\text { demonstrated in practice }\end{array}$} \\
\hline 7 & $\begin{array}{l}\text { Very strong or } \\
\text { demonstrated } \\
\text { importance of } \\
\text { one criterion } \\
\text { over } \\
\text { another }\end{array}$ & \\
\hline
\end{tabular}




\begin{tabular}{|l|l|l|}
\hline 8 & $\begin{array}{l}\text { Very, very } \\
\text { strong }\end{array}$ & $\begin{array}{l}\text { The evidence favoring one } \\
\text { criterion over another is of the } \\
\text { highest possible order of } \\
\text { affirmation }\end{array}$ \\
\hline $\begin{array}{l}\text { Extreme } \\
\text { importance on criterion } \\
\text { one andher } \\
\text { over another }\end{array}$ & $\begin{array}{l}\text { If activity A has one of the preceding numbers } \\
\text { assigned to it when compared with activity B, then } \\
\text { B has the reciprocal value when compared with A }\end{array}$ \\
\hline Reciprocals
\end{tabular}

Step 3: The pairwise comparisons of various criteria generated are organized into a square matrix.

Let $\mathrm{C}=\{C j \mid j=1,2, \cdots, n\}$ be the set of criteria. Equation (1) is the pairwise comparison shown by a square and reciprocal matrix.

$$
A=a_{i j}=\left(\begin{array}{ccc}
a_{11} & \ldots & a_{1 n} \\
\vdots & \ddots & \vdots \\
a_{n 1} & \cdots & a_{n n}
\end{array}\right)
$$

Step 4: The principal eigenvalue and the corresponding normalized right eigenvector of the comparing matrix give the relative importance of the various criteria being compared. The elements of the normalized eigenvector are termed weights with respect to the criteria or sub-criteria and ratings with respect to the alternatives. Equation (2) showed formula of each matrix that needs to be normalized.

$$
A_{w}=\lambda_{\max } \cdot W
$$

Saaty [28] demonstrated that $\lambda_{\max }=n$ is a necessary and sufficient condition for consistency. Inconsistency may arise when $\lambda_{\max }$ deviates from $n$ due to varying responses in the pairwise comparisons. Therefore, the matrix A should be tested for consistency by using the equation of (3) and (4).

$$
\begin{gathered}
C I=\frac{\left(\lambda_{\max }-n\right)}{(n-1)} \\
C R=\frac{C I}{R I}
\end{gathered}
$$

\section{Results and discussion}

Total population of 50 SMEs Food Processing Industry consists of 30 Small enterprises and 20 Medium enterprises. All the questionnaires distributed by e-mail, phone calls, and by hand and all 50 questionnaires returned. However, there are three respondents are not met consistency ratio less than 0.1 . Therefore, only 47 questionnaires are reliable, trustworthy and proceed to analysed.

The ranking of main criteria and sub-criteria shown in Table 2 and Table 3. From the perspective of SMEs respondents, the most important main criteria are cost (0.383), followed by quality (0.326), service (0.153), delivery (0.095) and management and organisation, (0.043) while purchase cost, audit result, defect analysis, transportation cost and fast responsiveness were the first five major sub-criteria with a global weight of 0.201 , $0.145,0.139,0.128$ and 0.082 respectively.

Table 2. The ranking of main criteria.

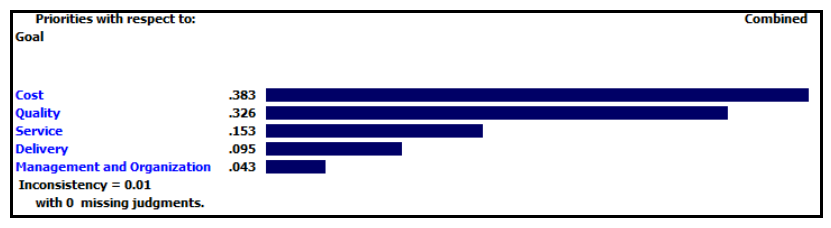

Table 3. The ranking of sub-criteria.

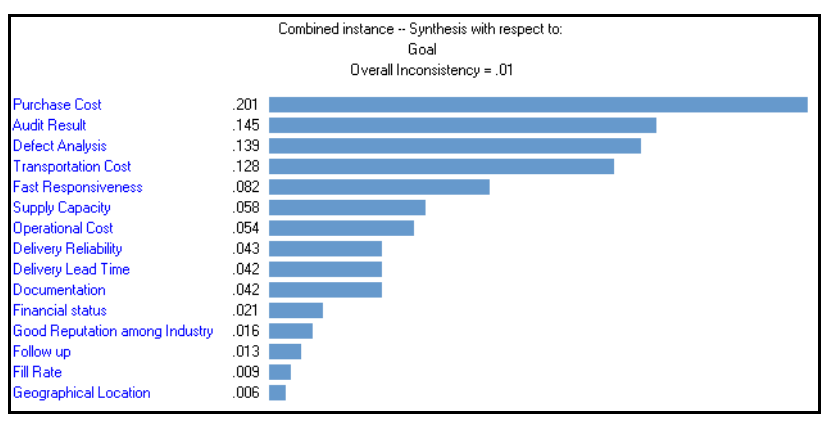

Based on criteria ranking in Table 4, obviously shows that SMEs strongly agreed that cost was the most priority criteria. This finding was similar with the research done by Choi \& Hartley [28]; Chan \& Niraj [29]; Magdalena [30] indicated that cost criteria is the most emphasis criteria that purchasing team will consider when they selecting supplier. Next, quality and service were ranked as second and third priority criteria. SMEs strongly agreed that quality of raw material supplied is an essential to make sure there are no any defect raw materials item that will be interrupt during the food production. Chan \& Niraj [29]; Ware et al. [31], indicated that quality provided by supplier has directly effect on production process and as well as end of product, therefore provided quality must be assessed carefully.

According to the SMEs perspective, service was the third priority criteria that they will consider when selecting supplier even they claimed that most of the time service provided by suppliers almost similar and they did not concern it too much. Sim et al. [32], Sagar \& Singh [19] summarized that company emphasizes service provided even most of the service provided by suppliers is similar with each other but supplier who able provides better customer services and maintain a good relationship in long term is more preferred. However, delivery and management and organization were fourth and fifth priority criteria. SMEs agreed that delivery and management and organization should be the last two considerations for supplier selection as these two criteria were would not be much emphasized by them.

The first five sub-criteria were purchase cost $(0.201)$, audit result (0.145), defect analysis (0.139), transportation cost $(0.128)$ and fast responsiveness (0.082). SMEs agreed that purchase cost is the most priority sub-criteria when selecting supplier as they have to choose a lower cost given by supplier in order increased quantity of food product manufactured. Transportation cost was ranked at fourth of cost criteria 
by SMEs as they have consider to minimize the expenses involved in moving ordered raw materials from location of supplier to company.

Moreover, SMEs agreed that audit result and defect analysis were important as they must review audit results of raw material supplied to determine the appropriate food safety practices at food processing industry and using defect analysis to determine the potential safety risks in food products and seek to reduce or eliminate them. Lastly, fast responsiveness was the fifth important sub-criteria that ranked by SMEs even there was different point of view from medium enterprises respondents which they ranked operational cost more important.

Table 4. Ranking value of supplier selection.

\begin{tabular}{|c|c|c|c|}
\hline Criteria (Rank) & Sub Criteria & Weight & $\begin{array}{l}\text { Global Weight } \\
\text { (Rank) }\end{array}$ \\
\hline \multirow{3}{*}{ Cost, 0.383 (1) } & Purchase Cost & 0.524 & $0.201(1)$ \\
\hline & $\begin{array}{l}\text { Transportation } \\
\text { Cost }\end{array}$ & 0.335 & $0.128(4)$ \\
\hline & Operational Cost & 0.142 & $0.054(7)$ \\
\hline \multirow{3}{*}{$\begin{array}{l}\text { Quality, } 0.326 \\
(2)\end{array}$} & Audit Result & 0.445 & $0.145(2)$ \\
\hline & Defect Analysis & 0.427 & $0.139(3)$ \\
\hline & Documentation & 0.128 & $0.041(10)$ \\
\hline \multirow{3}{*}{$\begin{array}{l}\text { Service, } 0.153 \\
\text { (3) }\end{array}$} & Supply Capacity & 0.376 & $0.058(6)$ \\
\hline & $\begin{array}{l}\text { Fast } \\
\text { Responsiveness }\end{array}$ & 0.537 & $0.082(5)$ \\
\hline & Follow Up & 0.087 & $0.013(13)$ \\
\hline \multirow{3}{*}{$\begin{array}{l}\text { Delivery, } 0.095 \\
\text { (4) }\end{array}$} & $\begin{array}{l}\text { Delivery } \\
\text { Reliability }\end{array}$ & 0.457 & $0.0043(8)$ \\
\hline & $\begin{array}{l}\text { Delivery Lead } \\
\text { Time }\end{array}$ & 0.448 & $0.042(9)$ \\
\hline & Fill Rate & 0.096 & 0.009 (14) \\
\hline \multirow{3}{*}{$\begin{array}{l}\text { Management } \\
\text { and } \\
\text { Organization, } \\
0.043(5)\end{array}$} & Financial Status & 0.489 & $0.021(11)$ \\
\hline & $\begin{array}{l}\text { Good Reputation } \\
\text { among Industry }\end{array}$ & 0.375 & $0.016(12)$ \\
\hline & $\begin{array}{l}\text { Geographical } \\
\text { Location }\end{array}$ & 0.136 & $0.006(15)$ \\
\hline
\end{tabular}

\section{Conclusions}

This research provided useful information and reference for the person who involved in process of selecting supplier or has the authority in supplier selection. The objective of this research is to determine the ideal criteria of supplier selection in SME food processing industry using AHP. A total of 47 collected questionnaires have been analysed by using Expert Choice Software. The results shows SMEs agreed that cost $(0.383)$, quality (0.326), service (0.153), delivery (0.095) and management and organisation (0.043) are important. Meanwhile, purchase cost (0.201), audit result (0.145), defect analysis (0.139), transportation cost $(0.128)$ and fast responsiveness $(0.082)$ are the first five sub-criteria ranking

The study cannot be generalised to the entire SMEs food processing companies in Malaysia since a survey was conducted among respondents in Batu Pahat, Johor areas only. Future study should be conducted in a representative sample of the SMEs food processing companies in Malaysia for a better understanding of ideal supplier selection.

\section{Acknowledgments}

This research is supported by Ministry of Higher Education of Malaysia (MOHE), under Exploratory Research Grant Scheme (ERGS) to the Universiti Tun Hussein Onn Malaysia. Grant number 045/phase I 2013.

\section{References}

1. C. M. Z. Che Omar, \& T. Anas, European Journal of Business and Social Science, 3(5), 76-87 (2014)

2. Global Agricultural Information Network. USDA Foreign Agricultural Service (2014). Retrieved May 24, 2015, from http://agriexchange.apeda.gov.in/marketreport/Repor ts/Food_Processing_Ingredients_Kuala_Lumpur_Ma laysia_-11-10-2014.pdf

3. S. S. Allam, M. F. M. Jani, Z. C. Senik, \& A. K. A. Domil, International Business Research, 4(1), 252 (2011)

4. N. R. N. M. Masdek, \& M. F. Othman, Economic and Technology Management Review, 9, 19-28 (2014)

5. M. K. Ghani, APO Multi-Country Study Mission,1145 (2004)

6. Mulyaningrum, B. Edna, \& J. Jabar, REACH UTEM conference, 2007 1-7 (2007)

7. S. C. Ting, \& D. I. Cho, Logistics Information Management, 16, 395-400 (2003)

8. C. Kahraman, U. Cebeci, \& Z. Ulukan, Logistics Information Management, 16(6), 382-394 (2003).

9. O. Larichev and D. Olson, Springer Science \& Business Media (2001)

10. R. Ramlan, \& W. K. Lee, $3^{\text {rd }}$ International Conference on Global Optimization and Its Application. pp. 150-160, (2014)

11. Y. Ahmad, \& D. S. Pirzada, SAGE Open, 4(4) (2014)

12. F. Tahriri, M. R. Osman, A. Ali, , R. Mohd Yusuff, \& A. Esfandiary, Journal of Industrial Engineering and Management, 1(2), 54-76 (2008)

13. W. Ren, \& N. Song, Second Pacific-Asia Conference on Web Mining and Web-based Application, 249-252 (2009)

14. M. Khalique, A. H. Md Isa, J. A. N. Shaari, \& A. Ageel,. International Journal of Current Research, 3(6), 398-401 (2011)

15. S. S. Omar, R. Ramlan, K. Ahmad, \& S. W. Chan, Advanced Science Letters, 21(5), 1089-1093 (2015).

16. K. Ayupp, \& R. Tudin,. International Journal of Business and Social Science, 4(16) (2013)

17. Malaysian Investment Development Authority. Industries in Malaysia (2013). Retrieved on March 23, 2013 from http://www.mida.gov.my/home/foodtechnology-and-sustainable-resources/posts/

18. Malaysian-German Chamber of Commerce \& Industry, Market Watch, Market Watch Malaysia 2010 Food Industry (2010). Retrieved April 5, 2015, from

http://malaysia.ahk.de/fileadmin/ahk_malaysia/Doku mente/Sektorreports/Market_Watch_2010/Food_201 0 _ENG_.pdf 
19. M. K. Sagar, \& D. Singh, International Journal of Engineering Research and Development, 4, 34-39 (2012)

20. W., Xia, \& Z., Wu, Omega. 35(5), 494-504 (2007)

21. L. Vijayvagy, International Journal of Management \& Innovation, 4(2) (2012)

22. J. L. Shen, Y. M. Liu, \& Y. L. Tzeng, Journal of Advanced Computational Intelligence and Intelligent Informatics, 16(5), 567-575 (2012)

23. C. O. Anyaeche, \& A. S. Abegunde, IOSR Journal of Mechanical and Civil Engineering, 9(1), 10-15 (2013)

24. A. Reza, R. Essmaeel, V. Hossein, \& H. P. Mohammad, International Journal of Current Life Sciences, 4(5), 1984-1988 (2014)
25. T. L. Saaty, Management science, 26(7), 641-658 (1980)

26. T. L. Saaty, RWS Publication 2 nd ed (pp. 73) (2006)

27. T. L. Saaty, Mathematics and computers in simulation, 20(3), 147-158 (1978)

28. T. Y. Choi, \& J. L. Hartley, Journal of Operations Management, 14(4), 333-343 (1996)

29. F.T.S. Chan, \& K. Niraj, Omega, 35, 417-431 (2007).

30. R. Magdalena, Asian J Technol Manage, 5(1), 1322(2012)

31. N. Ware, S. Sing, \& D. Banwet, Management Science Letters, 2(5), 1465-1490 (2012)

32. H. K. Sim, M. K. Omar, W. C. Chee \& N. T., 11th Asia Pacific Industrial Engineering and Management Systems Conference (2010) 